\title{
Participação pública na gestão urbana: o papel das universidades
}

Public participation in the management of cities: the role of universities

Participación pública en la gestión de las ciudades: el papel de las universidades

\section{Lucinda Oliveira Caetano}

Bolseira FCT SFRH/BD/110008/2015/ Investigadora colaboradora CIAUD

Doutoranda em Urbanismo - Faculdade de Arquitetura - Universidade de Lisboa, Portugal

lucinda.caetano63@gmail.com

\section{Rodrigo Cury Paraizo}

Pesquisador LAURD/PROURB Professor Doutor PROURB - Faculdade de Arquitetura e Urbanismo - Universidade Federal do Rio de janeiro rparaizo@gmail.com 


\section{RESUMO}

Num contexto global de fragilidade política em que mesmo as democracias neoliberais não são suficientemente representativas das sociedades humanas, a ideia de "governança urbana" surgida na Conferência das Nações Unidas - ECO 92, vinculada ao conceito de desenvolvimento urbano sustentável, desempenhou um papel importante na consciencialização sobre o direito à cidade, e, por conseguinte, a respeito da gestão cautelosa do território, da inclusão social e da participação pública. Esta comunicação pretende debruçar-se sobre a participação pública nos processos de gestão/ regeneração urbana e sobre as universidades públicas enquanto atores de mediação preferenciais nesses processos participativos. A metodologia utilizada baseou-se na análise crítica comparativa de estudos de caso sistematizados em bibliografia científica em contextos luso-brasileiros. Os resultados parecem comprovar que os processos de participação pública com mediação das universidades em contextos luso-brasileiros são mais comuns no Brasil do que em Portugal, e que incidem basicamente na "assistência técnica" a segmentos sociais de baixa renda, residentes em contextos urbanos de gênese ilegal. No entanto, o aporte técnico e de cidadania que esses processos de participação pública trouxeram a esses territórios "à margem" parece apontar um caminho para a construção coletiva das cidades, com participação ativa de toda a sociedade, usando como modelos de boas práticas as experiências em contextos urbanos fragilizados. As conclusões levam à premissa da mais valia da ampliação do papel mediador das universidades públicas, enquanto atores privilegiados dos processos participativos.

PALAVRAS-CHAVE: Governança urbana. Participação pública. Universidades Públicas.

\section{ABSTRACT}

In a global context of political weakness which the democracies integrated in new liberalism are not sufficiently representative of human societies the idea of "urban governance" emerged at the United Nations Conference - ECO 92, linked to the concept of sustainable urban development, have played an important role in raising awareness about the right to the city, as well as the necessary care in territory management and social inclusion and public participation. This communication is about on public participation in the management and regeneration urban and on public universities as preferred mediation actors in these participatory processes. The methodology used was based on the comparative critical analysis of case studies systematized in scientific literature in Brazilian Portuguese context. The results seem to prove that the public participation process with mediation of universities in Portuguese-Brazilian contexts are more common in Brazil than in Portugal, and that focus primarily on "technical assistance" to social groups of low-income residents in urban contexts illegal genesis. However, the technical and citizenship contribution that these public participation processes brought to these territories "on the margins" seems to point a path to the collective construction of cities, with active participation of the whole society, using as best practice models' experiences in urban contexts weakened. The findings lead to the premise of the added value of enlargement mediating role of public universities as key actors of participatory processes.

KEYWORDS: Urban Governance. Public participation. Public Universities.

\section{RESUMEN}

En un contexto global de debilidad política en que las democracias neoliberales no son representativas de las sociedades humanas, la idea de " gobernanza urbana" surgida en la Conferencia de las Naciones Unidas - ECO 92 en relación con el concepto de desarrollo urbano sostenible, desempeñó un papel importante en la concienciación sobre el derecho a la ciudad así como en la necesidad de una gestión cuidadosa del territorio, de la inclusión social y de la participación. Esta comunicación trata sobre la participación pública en el proceso de gestión / regeneración urbana y sobre las universidades públicas como actores preferidos de mediación en estos procesos participativos. La metodología utilizada se basa en el análisis crítico comparativo de estudios de casos estudiados y sistematizados en la literatura científica en contextos luso-brasileños. Los resultados parecen demostrar que el proceso de participación pública con la mediación de las universidades en contextos luso-brasileños son más comunes en Brasil que en Portugal, y que se centran principalmente en la "asistencia técnica" a los grupos sociales frágiles, residentes en contextos urbanos de génesis ilegal. Sin embargo, la contribución técnica y de ciudadanía que estos procesos de participación pública llevaron a estos territorios "en los márgenes" parecen señalar un camino para la construcción colectiva de las ciudades, con la participación activa de toda la sociedad, utilizando como modelos de buenas prácticas las experiencias en contextos urbanos debilitados. Los resultados conducen a la premisa del valor añadido de la expansión de la función mediadora de las universidades públicas como actores clave en estos procesos participativos.

PALABRAS CLAVE: Gobernanza Urbana. La participación del público. Universidades públicas. 


\section{INTRODUÇÃO}

O fato fundamental é que o neoliberalismo se tornou hoje a racionalidade dominante, não deixando da democracia liberal nada além de um envelope vazio, condenada a sobreviver na forma degradada de uma retórica ora 'comemorativa', ora 'marcial'. (DARDOT E LAVAL, 2016, p.384)

As democracias ocidentais neoliberais, nas suas formulações de base baseadas no binônimio "mercado e classe política", promovem sociedades concorrenciais excludentes, onde a representatividade do povo inerente ao conceito de democracia está cada vez mais ausente. (DARDOT E LAVAL, 2016). Essa exclusão muitas vezes reflete-se na supressão de direitos socias duramente conquistados, suprimidos de modo unilateral, sobre a égide da luta contra a crise económica ${ }^{1}$. Esse cunho "mercantil" das sociedades neoliberais promoveu - e ainda promove - a discussão sobre a aproximação entre cidadão e consumidor, que, por um lado, ajudou a alavancar a participação na sociedade brasileira, embora, por outro, contribua para obscurecer a real extensão do papel do cidadão, e sua participação ativa na comunidade, quando comparado ao papel mais passivo do consumidor de serviços.

Simultaneamente, e "aparentemente" em contrariedade aos ideais neoliberais de racionalização e eficiência, encontra-se a administração pública - burocrática, hierárquica, afastada da população a quem deve servir, mas que, de acordo com Alford e Friedland (1985), cumpre o seu propósito, pois é intrínseco à manipulação do poder as contradições entre as instituições políticas e as burocráticas, especialmente quanto menos democrático é o governo em questão, porque a complexidade processual e o afastamento dos processos decisórios colocam a população dependente das instituições políticas. As "causas" da "ineficiência" da administração publica apontadas na literatura científica variam. Podemos citar, por exemplo, a necessária mudança cultural transversal, ou como afirma Shaw:

As aspirações para o sistema de planeamento só podem ser realizadas se todos os envolvidos no processo de planeamento mudarem a maneira de pensar e trabalhar. Há, portanto, uma necessidade de uma mudança cultural nas atitudes e práticas de trabalho, talvez, também incluindo a reforma organizacional. (SHAW, 2006, p. 3; tradução nossa)'.

Outra causa possível seria a falta de tradição de uma gestão "aberta e participada", como referido por Portas et al, ao avaliar o estado da governança em Portugal.

A abertura das estruturas administrativas e de tomada de decisão à

\footnotetext{
${ }^{1}$ Como por exemplo o aumento do tempo de serviço para a aposentadoria (no Brasil e Portugal), a redução dos salários dos funcionários públicos (em Portugal), entre outras medidas criadas para "reduzir a despesa pública".

${ }^{2}$ No original: "These aspirations for the planning system can only be realized if all those involved in the planning process change the way they think and work. There is therefore a need for a cultural shift in attitudes and working practices, perhaps also including organizational reform".
} 
participação pública, à cooperação de agentes económicos e a outras instituições da sociedade civil não tem, porém, suficiente tradição em Portugal. (PORTAS et al, 2007).

Ou, ainda, conforme defende João Ferrão (2011) à "existência de um sistema de ordenamento do território jovem mas precocemente descredibilizado e de uma comunidade técnicoprofissional e científica disciplinarmente fragmentada". Além disso, é possível pensar que o caminho que vem sendo delineado pelas sociedades humanas, fruto dos valores produzidos pela "cultura neoliberal", na procura incessante de acumulação e consumismo (DARDOT E LAVAL, 2016), aliado à finitude dos recursos naturais que coloca em risco a preservação da espécie humana no planeta, tem promovido um debate teórico importante que poderá sinalizar uma mudança "socio-cultural" a nível global.

Na Conferência das Nações Unidas sobre o Ambiente e o Desenvolvimento realizada no Rio de Janeiro, em 1922, foram produzidos praticamente todos os documentos base para os temas que posteriormente foram sendo aprofundados, a nível mundial, europeu e nacionais, como por exemplo, a Agenda 21, que em linhas gerais reporta-se à sustentabilidade social, económica e ambiental (incluindo-se nesse conceito as questões urbanas, as alterações climáticas, as energias "amigas do ambiente", o equilíbrio territorial, a proteção da paisagem, a coesão social, a governança, as parcerias público-privadas, entre outras).

As conclusões da ECO 92 e as iniciativas sucessivas partiram de um diagnóstico global feito ao planeta, que em termos genéricos, como avaliado pelo grupo de peritos sobre o ambiente urbano (FUDGE et al, 1996) reportam-se à "crescente urbanização do mundo, associada a questões globais de alterações climáticas, escassez de água, degradação do ambiente, reestruturação económica e exclusão social", exigindo como referido "que olhemos com novos olhos o futuro das nossas cidades."

A problemática inerente às cidades e à mutação das sociedades ocidentais, promotoras de mudanças estruturais na maneira "de pensar e agir", da ciência e da técnica, das relações sociais, da economia, das desigualdades sociais e das formas de democracia "(...) implica transformações profundas na "concepão, produção e gestão de cidades e do território" (ASCHER, 2010, pp. 17 e 18). Mudanças, portanto, na configuração institucional das "cidades standard", no dizer de Cavallazi e Fauth (2014), ou seja, cidades de espaços padronizados na norma (e nas formas), de relações fragmentadas e fragilizadas com seus habitantese com a história por eles produzida, que com eles não dialoga, apenas ordena.

As diretrizes das políticas públicas territoriais, expressas na legislação, tanto no Brasil com o Estatuto da Cidade ${ }^{3}$, quanto em Portugal, através da Estratégia Cidades Sustentáveis $2020^{4}$

\footnotetext{
${ }^{3}$ Lei no 10.257 , de 10 de julho de 2001 e Lei no 6.766, de 19 de dezembro de 1979.

${ }^{4}$ Resolução do Conselho de Ministros n.o 61/2015, de 16 de Julho.
} 
para Portugal garantem o direito a cidades sustentáveis e à participação, mas a prática revela alguns problemas na operacionalização, tanto no Brasil $^{5}$, quanto em Portugal ${ }^{6}$. A exceção fica por conta de alguns casos particulares, como, por exemplo, a elaboração do Plano Diretor de Rio das Ostras (MIRANDA, 2006).

Entretanto, existem experiências de participação pública relevantes em curso, mediadas por instituições que não fazem parte da estrutura de governança, mais especificamente de Universidades portuguesas e brasileiras, que poderão servir de enquadramento em processos participativos. As universidades trazem um outro aporte institucional que pode servir de base para uma matriz participativa diferenciada, mais ágil em suas demandas mas ainda comprometida com os canais burocráticos oficiais.

Esta comunicação pretende debruçar-se sobre a participação pública nos processos de gestão/ regeneração urbana e sobre as universidades públicas enquanto atores de mediação preferenciais nesses processos participativos.

\section{O CONCEITO DE GOVERNANÇA URBANA}

Na linha da frente dessas tendências "inovadoras" encontra-se o conceito de "governança urbana", normalmente vinculado a um modo de governar baseado na transparência e participação pública.

A definição de governança contém em si um espectro tão abrangente que pode-se partir da definição genérica, e de certo modo simplista, de Dente et al (2005, apud CRESPO, 2013), que define governança como a "atividade destinada ao fim de governar".

Esta definição surge na sequência de uma análise interpretativa que relaciona os significados de "governabilidade", "governança" e "governo", onde "governabilidade" corresponderia à aptidão de determinado "governo" para definir coerentemente objetivos a alcançar e correspondente tomada de decisões, para a implementação de ações conducentes à sua materialização, no seu processo e percurso de "governança". Crespo (2013) ao debruçar-se sobre o pluralismo conceitual recorre a Dente et al (2005), que define "governança" como "conjunto de ações, práticas e processos que conotam o exercício do governo", enquanto o "governo" se refere ao "campo das instituições políticas e das estruturas organizativas".

No outro lado do espectro estaria Kooiman (2003), apud Hall (2011), que assume "governança" como a "totalidade das conceções teóricas sobre governar". Noutras palavras,

\footnotetext{
5 "Vale dizer que ainda é muito difícil fazer valer aas novas e democráticas regras de utilização social das cidades brasileiras" (SOMEKH in ASCHER, 2010, p. 14)

${ }^{6} \mathrm{Na}$ ótica de Crespo (2013), em Portugal a "governança" possui um impacto territorial ainda diminuto, apesar de se constituir como um instrumento útil na tomada de decisões pelo poder político, sendo um utensílio inclusivo de desenvolvimento urbano.
} 
verifica-se que "governança" passa a significar a totalidade das conceções teóricas sobre as várias "maneiras de governar", ou seja, preocupa-se mais com as ideologias subjacentes do que com as ações, práticas e processos que serão utilizados na atividade da governação, sendo, portanto, o universo oposto da definição anterior de Dente et al (2005).

No seu estudo, Hall (2011) analisa governança como conceito-chave nas políticas públicas, em especial, nas políticas de turismo, categorizando as tipologias e os elementos fundamentais, usando como estudo de caso a implementação pelos Estados (governos nacionais e territoriais) aderentes à Convenção sobre Diversidade Biológica (criada na ECO 92).

No documento acima referido, Hall (2011) define as estruturas de governança em quatro categorias distintas: Hierarquia; Comunidades; Redes e Mercados. Na sua ótica, usando como referencial essa grelha de análise parte de uma situação de controlo absoluto (hierarquias) para uma situação de autorregulação (comunidades) ou "não governo", conforme Figura 1.

Ressalvamos que a definição de comunidade aqui utilizada se refere a um grupo de cidadãos vinculados geográfica e culturalmente, ou seja, pretende-se salientar que não está necessariamente associada a grupos sociais fragilizados, residentes em assentamentos informais, como por norma vem sendo utilizado relativamente às "favelas" no Brasil. 0 conjunto das comunidades definiria o próprio conceito de "sociedade local" em termos de governança territorial.

Figura 1: Grelha tipológica de Governança de Hall

\begin{tabular}{|c|c|c|c|}
\hline HIERARQUIA & MERCADOS & REDES & COMUNIDADES \\
\hline
\end{tabular}

Fonte: ELABORAÇÃO CAETANO, 2015

Na visão de Hall (2011), essas tipologias funcionam de modo estanque. No entanto, conforme parece indiciar a investigação coordenada por um dos autores (Caetano et al, 2016), as tipologias atuam em conjunto e são interdependentes, com escalas de graduação.

Crespo (2013) analisou o processo de surgimento, características e causas da emergência de mecanismos e de instrumentos de governança urbana e os desafios à gestão territorial. 0 tema central da sua investigação foram os processos de governança urbana relacionados com as políticas públicas e com a gestão municipal, através de uma análise comparativa de municípios, inseridos no mesmo contexto territorial, neste caso a área metropolitana de Lisboa.

Em termos teóricos, percebe-se que Crespo (2013) opõe a ideia de governança "assumida como nova governação" ao modelo tradicional de governar, procurando encontrar influências e a utilização de instrumentos de gestão inovadores (relacionados com parcerias e participação pública) nas políticas públicas. A sua metodologia de investigação parte de 
análises empíricas para aferir em que medida Poder Político e Comunidades interagem para criar as políticas públicas.

O que importa reter é a premissa de que a "cidade" enquanto construção coletiva de uma sociedade será mais humana e justa quanto maior for a participação pública e que a própria definição de democracia ${ }^{7}$ implica participação ativa dos cidadãos nos processos de decisão.

\section{INSTITUIÇÕES MEDIADORAS DE PARTICIPAÇÃO POPULAR}

Existem diferenças substanciais em relação às instituições mediadoras de participação social no Brasil e em Portugal. No Brasil, a participação pública foi definida pela Constituição Federal de 1988 e implementada pelos Conselhos Municipais que conforme Cosenza (2016) ${ }^{8}$, aparecem como "espaços públicos que permitem a interação entre a sociedade civil e o Estado, proporcionando uma maior proximidade entre os cidadãos e seus gestores locais". Em Portugal, apesar da participação pública estar consagrada na legislação sobre urbanismo e ordenamento do território, ela se dá como procedimento processual, numa relação entre a Administração Pública e os cidadãos, cabendo à Administração o dever da Informação.

A participação social nas políticas do Estado no Brasil pode ocorrer através de Organizações Não Governamentais (ONGs), grupos de debate políticos regionais, associações populares e demais interessados. As instituições mediadoras de participação social nas políticas públicas brasileiras são os "conselhos gestores, em todas as instâncias da federação, que deliberam ou são consultados sobre as temáticas que representam saúde, educação, habitação, assistência social”, entre outros (PAES DE PAULA, 2005 apud COSENZA, 2016).

Como exemplo, podemos citar o Programa de Governança Solidária Local articulado com o Orçamento Participativo (NUNES, 2009), cujo objetivo era a promoção do desenvolvimento sustentável de suas regiões, territórios e bairros, incluindo a inclusão social (através da remoção de fronteiras interpostas por desigualdades internas) em parceria com as comunidades (estimulando a que a comunidade fosse protagonista), desencadeando a criação de programas integrados e prioritários em gestão transversal entre as diversas esferas governamentais, cuja gestão das ações era feita com base em indicadores de avaliação e monitorização.

Com a Governança Solidária Local, a Prefeitura ${ }^{9}$ procurou a partilha de agendas de desenvolvimento nas 17 regiões e nos 84 bairros de Porto Alegre, agregando "novas atitudes e

\footnotetext{
7 Democracia é o governo do povo. A palavra vem do grego, sendo formada por demos que quer dizer "povo" e kratos que tem como significado "poder". Assim, Democracia é o regime de governo em que o poder pertence ao povo e as decisões políticas visam o benefício do povo. In: https://www.significadosbr.com.br/democracia Consultado em 11/09/2016

${ }^{8}$ In http://ambito-juridico.com.br/site/index.php?n_link=revista_artigos_leitura\&artigo_id=16199 Consultado em $12 / 09 / 2016$

${ }^{9}$ As Prefeituras brasileiras são equivalentes às Câmaras Municipais portugueesas.
} 
práticas dos diversos atores sociais, e mostraram que, com essa forma de relacionamento, foi possível realizar, em conjunto, agendas locais de desenvolvimento.

Um Comitê Gestor Local atuou como uma rede governamental integrando todos os órgãos do governo municipal. Seus objetivos foram estimular ações de governança na sociedade e promover ações de endogovernança no governo municipal, agilizando o atendimento das demandas da população; fomentando uma cultura social de governança a respeito dos serviços públicos; adequando os programas integrados de governo às peculiaridades locais e promovendo a articulação entre Orçamento Participativo, governo e ações de governança. É um grupo multidisciplinar, coordenador e facilitador do processo de governança local (NUNES, 2009, p.70)

No caso português, como refere Ferrer (2012), os direitos dos cidadãos em matéria urbanística, que deveriam estar vinculados ao próprio conceito de cidadão (independentes do título da propriedade), fundamentam-se nos seguintes critérios: transparência na atuação administrativa; informação e participação dos cidadãos (referendo nacional ou a nível local); publicitação ativa da Administração Pública.

As instituições mediadoras de participação social nas políticas públicas portuguesas são os "conselhos locais", mas salvo casos específicos, como os Conselhos Locais de Ação Social ou Conselhos de Educação, é invulgar a constituição de Conselhos Locais de Urbanismo. Quando existem, são derivados de iniciativas autônomas dos Municípios, sem tradição ou sistematização a nível nacional.

A participação social nas políticas do Estado em Portugal também pode ocorrer através de Organizações Não Governamentais (ONGs), grupos de debate políticos regionais, associações populares e demais interessados.

É importante salientar que, neste trabalho, a participação pública está sendo avaliada como prática de cidadania ativa formal e estratégica. No entanto, existem exemplos "informais" e/ou pontuais muito interessantes, por aportarem metodologias de participação inovadoras, muitos deles com recurso a ferramentas de software, usualmente referente a ações de "fiscalização popular" para alerta de "incidentes no espaço urbano".

No Brasil, temos alguns casos onde as plataformas interativas (em geral, na forma de sistemas colaborativos baseados em mapas online) têm um papel preponderante, onde se destacaria o aplicativo para dispositivos móveis "Colab.re", criado em 2013 para encaminhar demandas locais da população para o governo municipal. Em 2015, era utilizado por 80 prefeituras como canal de atendimento online, permitindo ao cidadão Fiscalizar, Propor ou Avaliar o espaço urbano utilizando o celular, através da submissão de registos fotográficos identificados por meio do GPS e classificados de acordo com o tema da reclamação (NASCIMENTO, 2015; GOMES, 2016).

A Prefeitura do Rio de Janeiro desenvolveu um aplicativo semelhante, denominado "Portal 1746", para servir de canal de comunicação entre a população e os serviços municipais, cujo 
nome teve origem no sistema de contato telefônico que já era utilizado para essa finalidade; já a Prefeitura de São Paulo desenvolveu o TakeVista com valências semelhantes, "onde as ocorrências podem ser registadas por meio de áudio, foto ou vídeo, cujas coordenadas geográficas são registadas automaticamente pelo aplicativo para correta localização do evento". (NASCIMENTO, 2015, p.25 e 26)

Em Portugal também existem ações pontuais de "fiscalização popular" para alerta de "incidentes no espaço urbano", como por exemplo o Projeto Mãos à Obra do Programa de Regeneração Urbana POR TI, da empresa municipal de Portimão, com competências na área da reabilitação urbana, onde os cidadãos eram sensibilizados para participar, denunciando por telefone ou email anomalias detetadas no espaço público.

No Brasil, no âmbito da participação da sociedade de modo autônomo, também existem exemplos interessantes tais como o projeto Viva Favela, criado em 2001 pela ONG Viva Rio. Trata-se de um projeto de publicação de conteúdo jornalístico sobre as favelas produzido por seus moradores, compreendendo desde o site para disponibilização do conteúdo até cursos de formação dos correspondentes das comunidades faveladas ${ }^{10}$. Há ainda iniciativas como o Wikimapa, lançado em 2009, enquanto iniciativa da Rede Jovem (programa social da organização não-governamental Solidaritas) de mapeamento colaborativo de áreas socialmente excluídas (inclusive áreas excluídas das engines de busca web) no Rio de Janeiro, feito por jovens da própria comunidade mapeada, utilizando aparelhos celulares. Uma vez mapeados os pontos de interesse (escolas, bares e igrejas, por exemplo), eram publicados no site www.wikimapa.org.br ${ }^{11}$.

Na área cultural, em Portugal, podemos destacar o festival A Rota do Petisco, a decorrer desde 2011, dinamizado pela Associação Teia D'Impulsos, que consiste num roteiro gastronómico, envolvendo diversos restaurantes, em parceria com vários municípios constituintes da Bacia do Arade, mantendo na cidade de Portimão, local pioneiro do Petisco, o seu centro geográfico, constituindo-se como um novo modelo de governança baseado na ação da comunidade (CAETANO et al, 2016).

\section{O PAPEL DAS UNIVERSIDADES NA MEDIAÇÃO NO BRASIL E EM PORTUGAL}

No que concerne ao papel das universidades como mediadoras nos processos de participação pública, julga-se importante referir que no Brasil já há antecedentes jurídicos constituídos pela Lei Federal no 11.888/2008, que colocou em pauta a assistência técnica enquanto "ação voltada para o direito à moradia, como prática de planejamento politizado, insurgente e conflitual, considerando os diferentes agentes, interesses antagônicos, conflitos na apropriação do espaço e buscando alterar a produção e a reprodução do espaço urbano"

\footnotetext{
${ }^{10}$ Fonte: http://vivafavela.com.br/o-viva-favela/

${ }^{11}$ Fonte: http://fundacaotelefonica.org.br/noticias/mapeando-minha-area-fundacao-telefonica-e-rede-jovemlancam-o-wikimapa-no-rio-de-janeiro/
} 
(BIENENSTEIN et al, 2016, p.2). Nesse âmbito, no Brasil foram elaborados estudos com uma quantidade considerável de ações de mediação participativa de Instituições de Ensino com comunidades residentes em assentamentos informais, onde se verifica o empoderamento das populações locais e muitas vezes garantiu o apoio técnico que permitiu a permanência desses núcleos habitacionais.

Como estudos de caso, podemos citar as seguintes experiências:

- Apoio técnico da Universidade Federal Fluminense (UFF) aos moradores da Favela do Gato, São Gonçalo iniciada nos anos 1980, ameaçados de remoção pelas obras da rodovia BR-101 (Niterói-Manilha) (BIENENSTEIN et al, 2016, p.2);

- Apoio técnico da Universidade Federal da Paraíba aos moradores da Comunidade do Porto do Capim, em João Pessoa (que desde 1985, convivem com o risco de remoção, decorrente de uma política de higienização e de espetacularização do centro histórico), com a mediação do Ministério Público Federal, em 2015, para coordenar um processo participativo visando a construção conjunta de um projeto alternativo para a requalificação da área (ROMANO et al, 2016, p. 2);

- Apoio técnico do NEPLAC/ETTERN/IPPUR/UFRJ (Núcleo Experimental de Planejamento Conflitual do Laboratório Estado, Trabalho, Território e Natureza do Instituto de Pesquisa e Planejamento Urbano e Regional da Universidade Federal do Rio de Janeiro) e do NEPHU/UFF (Núcleo de Estudos e Projetos Habitacionais e Urbanos da Universidade Federal Fluminense) para a preparação do PLANO POPULAR DA VILA AUTÓDROMO, em parceria com os moradores, ameaçados pela Prefeitura de remoção, com a justificação da necessidade de ampliar as Avenidas Abelardo Bueno e Salvador Allende para a realização das Olimpíadas de 2016 (ASSOCIAÇÃO DE MORADORES E PESCADORES DA VILA AUTÓDROMO, s.d.) (BIENENSTEIN et al, 2016, p.2)

Em Portugal também temos exemplos de mediação em processos participativos, nomeadamente, do grupo GESTUAL, responsável pela organização de "workshops de participação", no quadro das Parcerias para a Regeneração Urbana (PRU) da Vertente Sul de Odivelas (VSO), cujo território incorpora cinco bairros delimitados como "áreas urbanas de génese ilegal”, no quadro da Lei n.o 91/95 (RAPOSO et al, 2012).

A metodologia utilizada baseou-se na análise crítica comparativa de estudos de caso sistematizados em bibliografia científica em contextos luso-brasileiros, ou seja, partindo dos estudos de casos realizados por outroos investigadores encontrar semelhanças, diferenças ou até um fio condutor que os interligue.

Os três estudos de caso brasileiro reportam-se a ações de assistência técniica a comunidades fragilizadas, para permitir a resistência a iniciativas do poder local que colocava em risco a pemanência da comunidade, ou seja, os "clientes do projeto" eram as comunidades. 
Os resultados desse cruzamento bibliográfico demonstram que quando os processos de participação pública com mediação das universidades ocorrem no âmbito da "assistência técnica" a segmentos sociais de baixa renda, residentes em contextos urbanos de gênese ilegal auxiliam a impedir a exclusão social, ou noutras palavras ajudam a incluir a "cidade dos pobres" à outra cidade.

No entanto, quando os processos são encomendados pelo poder local para permitir a conciliação de interesses dos diversos atores apresenta fragilidades decorrentes dos "conflitos de interesses" dos vários atores e provavelmente da falta de tradição da participão pública.

Contudo o aporte técnico e de cidadania que esses processos de participação pública trouxeram a esses territórios "à margem" parece apontar um caminho para a construção coletiva das cidades, se houver participação ativa de toda a sociedade.

\section{CONCLUSÕES}

A leitura dos estudos de caso face à grelha tipológica de Hall, conforme Quadro 2, confirma a nossa premissa de que a "cidade" enquanto construção coletiva de uma sociedade será mais humana e justa quanto maior for a participação pública e que a própria definição de democracia implica participação ativa dos cidadãos nos processos de decisão, ou seja, quanto maior for a incidência nas tipologias da governança.

Quadro 2: Aplicação das tipologias de Governança aos estudos de caso

\begin{tabular}{|c|c|c|c|c|}
\hline $\begin{array}{l}\text { Tipologia de } \\
\text { Governança }\end{array}$ & Projeto Pendotiba & $\begin{array}{l}\text { Projeto Porto de } \\
\text { Capim }\end{array}$ & $\begin{array}{c}\text { Plano Popular da Vila } \\
\text { Autódromo }\end{array}$ & $\begin{array}{c}\text { Parceria para a Regeneração } \\
\text { Urbana (PRU) da Vertente Sul } \\
\text { de Odivelas }\end{array}$ \\
\hline $\begin{array}{l}\text { Hierarquia } \\
\text { (Administração } \\
\text { Pública) }\end{array}$ & Governo do Estado & $\begin{array}{l}\text { Ministério Público } \\
\text { Federal; } \\
\text { Prefeitura de João } \\
\text { Pessoa } \\
\end{array}$ & $\begin{array}{c}\text { Governo do Estado do Rio } \\
\text { de Janeiro; } \\
\text { Prefeitura do Rio de } \\
\text { Janeiro } \\
\end{array}$ & Município de Odivelas \\
\hline $\begin{array}{l}\text { Mercados } \\
\text { (Agentes } \\
\text { económicos) }\end{array}$ & - & - & - & $\begin{array}{l}\text { Agentes económicos da área } \\
\text { de intervenção }\end{array}$ \\
\hline $\begin{array}{l}\text { Redes } \\
\text { (Parcerias) }\end{array}$ & $\begin{array}{l}\text { Universidade } \\
\text { Federal } \\
\text { Fluminense; } \\
\text { Associação de } \\
\text { moradores; } \\
\text { Federação das } \\
\text { Associações do } \\
\text { Município de } \\
\text { Niterói } \\
\end{array}$ & $\begin{array}{l}\text { Ministério Público } \\
\text { Federal; } \\
\text { Universidade Federal } \\
\text { da Paraíba; } \\
\text { Universidade Federal } \\
\text { da Bahia; } \\
\text { Associaçção das } \\
\text { Mulheres }\end{array}$ & $\begin{array}{l}\text { Universidade Federal } \\
\text { Fluminense; } \\
\text { Universidade Federal do } \\
\text { Rio de Janeiro, } \\
\text { Associação de } \\
\text { Moradores; } \\
\text { Grupo de Apoio; } \\
\text { Agência de Fomento e } \\
\text { Avaliação }\end{array}$ & $\begin{array}{c}\text { Poder local; } \\
\text { Técnicos Municipais; } \\
\text { Administração Central; } \\
\text { Investig. Universitários; } \\
\text { Equipa Técnica; } \\
\text { Comissões de Administração } \\
\text { Conjunta }\end{array}$ \\
\hline $\begin{array}{l}\text { Comunidades } \\
\text { (Cidadania Ativa) }\end{array}$ & $\begin{array}{l}\text { Comunidade da } \\
\text { Favela do Gato }\end{array}$ & $\begin{array}{c}\text { Comunidade de Porto } \\
\text { de Capim }\end{array}$ & $\begin{array}{l}\text { Comunidade da Vila } \\
\text { Autódromo }\end{array}$ & $\begin{array}{c}\text { Grupos sociais residentes; } \\
\text { Proprietários }\end{array}$ \\
\hline
\end{tabular}

Fonte: ELABORAÇÃO PRÓPRIA, 2016 
Por outro lado, verifica-se o contributo das Universidades nestes processos colaborativos para a construção coletiva de territórios, através da conjugação de interesses dos diversos atores envolvidos e fomentando a cidadania ativa.

Face a isso julga-se que a ampliação da atuação das universidades como mediadoras na participação pública proativa nos processos urbanísticos com a sociedade em geral poderá servir como um pilar fundamental na promoção da cidadania e na construção coletiva das cidades, para além de servirem como modelos de boas práticas para o desenvolvimento de modelos participativos de governança urbana a serem implementados pela Administração Pública.

\section{AGRADECIMENTOS}

Os autores gostariam de agradecer ao PROURB e à sua coordenadora Professora Doutora Eliane Bessa por todo o apoio dado às investigações em curso.

À Faculdade de Arquitetura da Universidade de Lisboa por viabilizar o estágio doutoral da autora Lucinda Caetano no PROURB/ UFRJ, sob supervisão do autor Professor Doutor Rodrigo Paraízo.

À Fundação de Ciência e Tecnologia de Portugal por financiar a investigação de doutoramento, incluindo a deslocação ao Brasil para a realização do estágio doutoral da autora Lucinda Caetano.

\section{REFERÊNCIAS BIBLIOGRÁFICAS}

ALFORD, R. R. e FRIEDLAND, R. Powers of theory: Capitalism, the State, and democracy. Cambridge University Press. Cambridge, 1985.

ASCHER, François. Os novos princípios do urbanismo. tradução e apresentação Nádia SOMEKH - São Paulo: Romano Guerra, 2010

ASSOCIAÇÃO DE MORADORES E PESCADORES DA VILA AUTÓDROMO. Plano Popular da Vila Autódromo - Plano de Desenvolvimento Urbano, Económico, Social e Cuultural, s.d.

BIENENSTEIN, Regina; BIENENSTEIN, Glauco e FREIRE, Eloísa Helena. Limites e Possibilidades da Assessoria Técnica na Luta pelo Direito à Moradis e à Cidade. ANAIS... IV Encontro da Associação Nacional de Pesquisa e Pós-Graduação em Arquitetura e Urbanismo. 2016. 16 p.

CAETANO, Lucinda Oliveira; CORREIA, Rafael L. C. e CASIMIRO, José Paulo. A cidade feita de sonhos - A outra face do Algarve. O cluster dos festivais nos cascos urbanos antigos. Estudos de caso: Faro, Loulé, Portimão e Lagos. ANAIS... do Seminário Internacional A Cidade Não Adormece. ISBN: 978-972-934643-9. 2016. p. 177-188.

CAVALLAZI, Rosângela Lunardelli e FAUTH, Gabriela. Cidade Standard e Vulnerabilidades em Processos de Precarização: Blindagens ao Direito à Cidade. ANAIS... III Encontro da Associação Nacional de Pesquisa e Pós-Graduação em Arquitetura e Urbanismo. 2014. 10 p.

COSENZA, Liz Zumaeta Costa. A importância da participação popular através dos conselhos municipais na formulação e aplicação de políticas públicas no âmbito local. Revista Âmbito Jurídico. 2016. 
Disponível em Âmbito Jurídico.com.br

CRESPO, José Luís. Governança e território. Instrumentos, métodos e técnicas de gestão na Área Metropolitana de Lisboa. Doutoramento em Urbanismo - FTL - UTL, Lisboa, 2013.

DARDOT, Pierre e LAVAL, Christian. A Nova Razão do Mundo. Ensaio sobre a Sociedade neoliberal. Tradução Madalena Echalar. 1. Ed. - São Paulo: Boitempo, 2016.

FERRÃO, João. O Ordenamento do Território como Política Pública. Lisboa: Ed. Fundação Calouste Gulbenkian, 2011.

FERRER, M. L. Los derechos de información y de participación ciudadanas em matéria urbanística. Tesis doctoral - Universidad de Girona, Programa de Doctorado en Turismo, Derecho y Empresa, Girona, 2012.

FUDGE, C.; SMOOK, R. e SOUGAREVA, N. Relatório Cidades Europeias Sustentáveis - Grupo de Peritos sobre o Ambiente Urbano (Publicado pela Comissão Europeia). DG XI - Ambiente, Segurança Nuclear e Protecção Civil. Bruxelas, 1996.

GOMES, Margarida Maria Mussa Tavares. Urbanismo colaborativo: ambientes digitais interativos e coprodução do espaço na cidade do século XXI. 2016. 197 f. Doutorado em Urbanismo - UFRJ, Rio de Janeiro, 2016.

Disponível

em: <http://minerva.ufrj.br/F/LPV9PMJTX8624L7NUHL4MB6ADP91GFQMCIINA1S4A61DUV55DL61941 ?func=full-set-set $\&$ set_number=004809\&set_entry=000001\&format=999>.

HALL, C. M. A typology of governance and its implications for tourism policy analysis. Journal of Sustainable Tourism 19. 2011, p. $437-457$.

KOOIMAN, J. Governing as governance. Sage, Los Angeles, 2003.

MAIA, Flavia Neves. Crowdurbanismo: potencialidades e limitações da mobilização digital para intervenções urbanas. 2013. 221 f. Mestrado em Urbanismo - UFRJ, Rio de Janeiro, 2013. Disponível em: <http://minerva.ufrj.br/F/LPV9PMJTX8624L7NUHL4MB6ADP91GFQMCINA1S4A61DUV55DL01152 ?func $=$ full-set-set $\&$ set_number $=004825 \&$ set_entry $=000001 \&$ format $=999>$.

MIRANDA, Maria Clara Ferreira de. Gestão Democrática da Cidade e Plano Diretor: o Caso-Referência da Cidade de Rio das Ostras. 2006. 271 f. Mestrado em Direito - PUC, Rio de Janeiro, 2006.

NASCIMENTO, Fernando Pacheco do. Mapas Colaborativos e o Espaço Público. A utilização de sistemas de mapeamento colaborativo online como ferramenta nos processos de requalificação urbana. 2015. Mestrado - Universidade Federal de Minas Gerais, Escola de Arquitetura. Belo Horizonte, 2015.

NUNES, L. N. de. 2009. Modelos de Democracia implementados em Porto Alegre: Experiências de Governança e Participação Cidadã. Mestrado em Ciências Sociais - PUC. Rio Grande do Sul, 2009.

PORTAS, N.; DOMINGUES; Á. e CABRAL, João. Políticas Urbanas - Tendências, estratégias e oportunidades. Lisboa: Ed. CEFA/ FCG, 2007.

RAPOSO, Isabel, CAROLINO, Júlia, CRESPO, José Luís, JORGE, Sílvia, PESTANA, Joana e VALENTE, Ana. Os Instrumentos Urbanísticos como Arena Social e a Percepção do Direito à Cidade: A Regeneração Urbana da Vertente Sul de Odivelas. ANAIS... VII Congresso Português de Sociologia. 2012. 15 p.

ROMANO, Elisabetta, FURTADO, Camilla; SIMÕES, Ezio Luiz Martins; BOAVENTURA, Flávio e FONTENELE, Marina. Experiência de Nucleação da Residência AU+E/UFBA na UFPB. ANAIS... IV Encontro da Associação Nacional de Pesquisa e Pós-Graduação em Arquitetura e Urbanismo. 2016. 20 p.

SHAW, D. Cultural Change and Planning Literature Review. Spatial Plans in Practice: Supporting the reform of local planning. Communities and Local Government Publications. London, 2006. 